\title{
“FESSORA, NÃO TEM INTERNET, NÃO?”- O USO DO COMPUTADOR, SEM INTERNET, COMO UM RECURSO NO ENSINO DE LÍNGUA INGLESA.
}

\section{“TEACHER, THERE'S NO INTERNET?” - THE USE OF COMPUTER, WITHOUT INTERNET, AS A RESOURCE IN ENGLISH LANGUAGE TEACHING.}

\author{
Angelita Duarte da Silva ${ }^{1}$ - IF Goiano - Campus Urutaí \\ Eliane Carolina de Oliveira² - UFG
}

RESUMO: Este artigo é um recorte de uma pesquisa de Pós-Graduação Lato Sensu que tem como tópico o uso do computador em aulas de língua estrangeira - inglês - na rede oficial de ensino de Goiás. Para realizar a investigação, foi conduzido um estudo de caso com um grupo de alunos do $2^{\circ}$ ano do ensino médio de uma escola da rede estadual de ensino, cujo objetivo foi verificar as possibilidades de uso do computador como um recurso no ensino da língua inglesa sem, necessariamente, estar interligado à internet. Este trabalho está embasado teoricamente em autores como Vygotsky (1998, 2001), do qual utilizamos a teoria sociointeracionista e, em relação ao uso do computador no ensino, buscamos apoio em autores como Moran (1995), Masetto (2000), Behrens (2000), Paiva (2008), entre outros. Os resultados apontam que, de fato, não só podemos realizar um bom trabalho utilizando o computador mesmo sem o uso da internet durante as aulas, como também oportunizar aos alunos o contato com esse recurso e motivá-los a aprender a língua inglesa.

\footnotetext{
${ }^{1}$ Mestranda do Programa de Pós-Graduação em Letras e Linguística da Faculdade de Letras, da Universidade Federal de Goiás e professora de português, inglês e libras do Instituto Federal Goiano - Campus Urutaí. Email: angeldss@hotmail.com e direção postal: Rodovia Geraldo Silva Nascimento, Km. 2,5, Zona Rural, Urutaí, Goiás. CEP: 75.790-000

${ }^{2}$ Doutora em Linguística Aplicada pela UFMG e Professora Adjunto 2 da Faculdade de Letras da UFG. Orientadora do trabalho. Email: ecaol2@yahoo.com
} 
Palavras chaves: Computador e educação, sociointeracionismo e aprendizagem de língua estrangeira.

ABSTRACT: This article is part of a study carried out in a Lato Sensu post-graduate course. It focuses on the use of computers in foreign language classes - English - in the official teaching network of Goiás. To carry out the investigation, we conducted a case study in a state school with a group of high school students in the 2nd year. Our aim was to investigate the possibilities of using the computer as a resource in English teaching without necessarily being connected to the internet. This work is theoretically based on authors such as Vygotsky (1998), from whom we use the sociointeractionist theory. Regarding the use of computers in education, we have the support of authors such as Moran (1995), Masetto (2000), Behrens (2000) and Paiva (2008), among others. The results show that, in fact, not only can we carry out good work by using the computer without internet connection, but we can also provide the students with opportunities to be in contact with this device and motivate them to learn the foreign language as well.

Keywords: Computer and education, socialinteractionist theory, foreign language learning.

\section{Introdução}

De acordo com os Parâmetros Curriculares Nacionais para o Ensino Médio (PCNEM, 2000), existe uma distância entre a velocidade com que a tecnologia evolui e como a sociedade evolui, fazendo, assim, que necessitemos de mudanças curriculares que primem por competências que envolvam a obtenção e a utilização de informações e mostrem aos nossos alunos as tecnologias ao nosso redor, ou seja, sensibilize-os para isso.

De acordo com a visão sociointeracionista proposta por Vygotsky (1998), vemos que o aluno aprende através da interação com outras pessoas e por meio do uso de ferramentas que favorecem a realização de atividades que possibilitem seu desenvolvimento cognitivo. Nesse sentido, a proposta deste trabalho foi fazer uso de programas de computador como ferramentas que, de maneira cooperativa, pudessem ser utilizadas para a aprendizagem de língua inglesa. 
Pensando nesses aspectos, a investigação centrou-se na seguinte pergunta: De que forma o computador pode ser um recurso eficiente a ser utilizado nas aulas de língua inglesa, sem depender de internet, para motivar nossos alunos?

Além desta introdução, este artigo contém, a seguir, o suporte teórico sobre a aprendizagem em um contexto de transformações, a teoria sociointeracionista e o uso do computador no ensino, em seguida, a apresentação da metodologia utilizada na pesquisa, a análise dos dados e, por fim, algumas considerações finais.

\section{Aprendizagem em um contexto de transformações}

Não só na área de educação, mas na sociedade como um todo, temos assistido e participado, nas últimas décadas, de mudanças profundas no campo da informação e do conhecimento proporcionadas pelo progresso tecnológico. As novas tecnologias de informação e comunicação (TICs) possibilitam não só mudanças diárias no cotidiano das pessoas e nas suas relações sociais, mas também delineiam novos espaços e fontes de aprendizagem no campo educacional (MORAN, 2000).

Observa-se que, fora do espaço escolar, o conhecimento e a informação estão cada vez mais ao alcance dos estudantes por meio de outros recursos: a televisão a cabo/satélite, os $D V D$ s, os $C D$-ROMS e a rede internet se tornaram fontes às quais os alunos podem ter acesso às mais variadas informações. O desenvolvimento tecnológico proporciona, assim, uma nova dimensão ao processo educacional e, consequentemente, exige dos professores e alunos transformações em seus papéis e a adoção de novas competências, dentre elas, o uso da tecnologia como ferramenta a serviço da aprendizagem.

Temos consciência que a tecnologia per se não é o fator mais importante na mudança paradigmática exigida na atualidade. Como afirmado por Paiva (2008), cada nova tecnologia buscou inserir na escola, especificamente no ensino de línguas, novas ferramentas nas práticas pedagógicas em uma tentativa de melhorar a mediação entre o aprendiz e a língua estrangeira. Em relação ao uso de recursos tecnológicos no ensino de línguas estrangeiras, a autora complementa declarando que o próprio livro sofreu problemas de ordem econômica e de rejeição que hoje são experienciados, de forma 
semelhante, pela introdução do computador em nossa sociedade. Seja a partir dos manuais de gramática, dos gravadores e fitas cassetes utilizados nos laboratórios de língua, passando pelas tecnologias de áudio e vídeo, a autora afirma que o "homem está irremediavelmente preso às ferramentas tecnológicas em uma relação dialética entre a adesão e a crítica ao novo”.

Como professores, observamos hoje que as possibilidades de ampliarmos e diversificarmos os tempos, os espaços, as oportunidades de interação e os recursos pedagógicos utilizados no processo de ensino-aprendizagem são cada vez mais frequentes e concretas. Nesse contexto de transformações, é preciso, então, repensar a sala de aula, refletir sobre os ambientes de ensino/aprendizagem e reconfigurar conceitos e práticas. Dessa forma, concordamos com Martins Fontes (2002, p. 18) quando ela afirma ser necessário “retomar os princípios de aprendizagem como processo sócio-histórico dentro das novas condições de produção de conhecimento, de um novo contexto de construção de saberes e com uma nova geração de aprendizes que (re)conhece o teclado e o lápis simultaneamente.”

Outro importante argumento é o de Moran (2000, p. 24) cuja afirmação é de que “o conhecimento se dá fundamentalmente no processo de interação, de comunicação. A informação é o primeiro passo para conhecer. Conhecer é relacionar, integrar, contextualizar, fazer nosso o que vem de fora”. Segundo o autor, é pela interação que entramos em contato com tudo o que nos rodeia, captamos as mensagens, nos revelamos e ampliamos a percepção externa. No entanto, a compreensão só é completa com a interiorização, com o processo de síntese pessoal e de reelaboração de tudo o que captamos por meio da interação. Tal argumento nos remete a Vygotsky e sua teoria de que a criança aprende através da interação com o ambiente que a rodeia.

\section{O sociointeracionismo e o uso do computador}

Vygotsky (2001) defende o papel do ambiente social na construção do conhecimento e na aprendizagem. Ele tem uma visão sócio-construtivista do desenvolvimento, sendo a mediação um dos conceitos fundamentais da sua teoria. Na ótica 
vygotskiana, o desenvolvimento do indivíduo resulta de um processo sócio-histórico no qual a aquisição de conhecimentos ocorre mediante a interação do sujeito com o meio em que está inserido (sociointeracionismo). Essa interação é sempre uma atividade mediada e, no âmbito da aprendizagem escolar, o professor e os colegas com maior experiência são os principais mediadores.

De acordo com Vygotsky (1998), em sua teoria sociointeracionista, o aprendiz é capaz de realizar atividades mais complexas com a ajuda do outro, ou seja, de alguém ou algo que dê suporte para que ele possa realizar atividades mais complexas. Isso acontece devido ao que o autor chama de Zona de Desenvolvimento Proximal ou ZDP ${ }^{3}$. Lantolf (2000) afirma que Vygotsky considera significativo o papel das ferramentas no entendimento que os indivíduos fazem em relação ao mundo e eles próprios. Seja por intermédio de signos formados pela linguagem verbal, por gestos, a escrita, desenhos, diagramas e outros, seja por artefatos criados pelos grupos sociais através dos tempos como, por exemplo, o cinzel, o lápis e o teclado do computador, os seres humanos não agem diretamente sobre o mundo físico sem o intermédio de ferramentas. Estas, de acordo com Vygotsky, são artefatos criados pelos seres humanos em um âmbito cultural específico e em condições históricas também específicas que, como tal, trazem consigo as características da cultura em questão. Tais ferramentas são utilizadas como auxiliares na resolução de problemas que não poderiam ser resolvidos da mesma forma em sua ausência. Por sua vez, elas também exercem influência sobre os indivíduos que as utilizam, na medida em que lhes possibilitam conhecer fenômenos e realizar atividades anteriormente desconhecidas.

Paiva (2008) afirma que o suporte oferecido ao aprendiz está presente de maneira direta e indireta nos processos de ensino. Diretamente através de atividades de trabalho, lúdicas ou educacionais e indiretamente, em artefatos como o livro, o computador, a arte

\footnotetext{
3 a ZPD pode ser definida como a distância entre o nível de desenvolvimento real, que se costuma determinar através da solução independente de problemas, e o nível de desenvolvimento potencial, determinado através da solução de problemas sob a orientação de um adulto ou em colaboração com companheiros mais capazes.
} 
etc. Em ambos os casos, o outro, ou seja, o suporte que é oferecido ao aprendiz, serve como um andaime, ou seja, um apoio para a aprendizagem do aluno.

Nesse sentido, percebemos em Vygotsky (1998), que a aprendizagem é mediada por sinais, símbolos, técnicas e outros instrumentos, dentre os quais, pensamos que seja possível incluir o computador, pois ele é um recurso que pode auxiliar o aluno a resolver problemas se o professor souber oferecer orientações, meios e recursos e acompanhá-lo na construção do conhecimento.

Martins Fontes (2002) complementa afirmando que, para que ocorra esse processo de aprendizagem, é necessário haver um processo de mediação pedagógica, ou seja, uma troca de saberes e construção conjuntas a partir de uma situação específica. Nesse sentido, Masetto (2000, p. 145) nos revela que a mediação pedagógica é o conjunto de características como atitude e comportamento do professor que se coloca como facilitador, incentivador ou motivador da aprendizagem, o qual se mostra como uma ponte entre o aluno e sua aprendizagem; uma ponte que colabora de forma ativa para que o aluno chegue aos seus objetivos.

Ainda pensando na mediação pedagógica, Moran (1995) advoga que o uso do computador não muda a relação entre professor e alunos, pois ela reforça uma visão conservadora, individualista ou progressista. Ou seja, as novas tecnologias não substituem o professor, apenas fazem com que sua função mude. Ele assume o papel de alguém que estimula a curiosidade do aluno, questiona, contextualiza os resultados, enfim, transforma a informação, que pode ser adquirida em bancos de dados, livros, CDs etc., em conhecimento.

Pennington (1996) aponta que o uso do computador no ensino de línguas oferece vantagens que podem ser divididas em três grupos:

- físicas: pois o computador permite que informações sejam obtidas com menor esforço físico. Existe aí uma economia de energia física.

- psicológicas: motiva os alunos na execução de tarefas devido ao caráter lúdico das atividades desenvolvidas utilizando o computador, o que favorece a criatividade, além de preservar a face do aluno, por oferecer 
privacidade na realização das tarefas, diminuindo, assim, a timidez de participar das aulas.

- cognitivas: o fornecimento de informações é mais rico, pois pode vir de várias formas, devido à combinação de informações linguística, visual e sonora, o que, por sua vez, segundo a autora, pode favorecer a ativação de esquemas mentais dos alunos.

Behrens (2000) salienta que o professor precisa utilizar a informática como instrumento de sua prática pedagógica, consciente de que a lógica do uso não pode ultrapassar a lógica da produção do conhecimento. Assim, para a autora, o computador e a rede devem estar a serviço da escola e da aprendizagem.

De acordo com Behrens (ibid), podemos utilizar os editores de textos, os quais são programas que permitem escrever, ajustar, transferir, copiar, recortar, compor, modificar, decompor, gravar e imprimir todos os tipos de textos. A maioria dos editores de textos oferece combinações de diferentes tamanhos, estilos e tipos de fontes. Alguns programas, como o Microsoft Word, permitem a inserção de imagens, desenhos e gráficos nos textos. A composição dos textos pode beneficiar-se dos recursos do próprio programa ou inserir recursos de outros aplicativos que são levados para dentro do texto.

Behrens (2000) também nos mostra que além dos editores de textos, pode-se encontrar programas de criação de apresentações que podem ser explorados com fins didáticos. Como, por exemplo, o Power Point, que possibilita a produção de slides que podem ter textos, imagens e gráficos, e que podem ser usados em palestras, aulas, encontros, ao serem projetados pelo datashow ou por equipamento semelhante. Os slides criados podem ser impressos e convertidos em transparências para serem utilizados em retroprojetor.

Ainda sobre o uso do Power Point, Masetto (2000) aponta que, mesmo com exemplos de novas técnicas, é interessante utilizá-lo em aula como recurso facilitador e mediador de aprendizagem, pois possui técnicas que integram imagem, luz, som, texto, movimento, pesquisa, busca, links já organizados nele próprio.

Masetto (2000) lembra que o Power Point não pode substituir as atividades do aprendiz, pois é necessário que se prevejam atividades, tempo, momentos para o aluno 
perguntar, refletir, debater, pesquisar, trabalhar, redigir etc. O Power Point deve, então, funcionar como incentivador dessas várias atividades de aprendizagem.

Behrens (2000) nos mostra ainda que as atividades didáticas que contemplam a tecnologia da informação fazem com que o aluno possa ir além da tarefa proposta, em seu ritmo próprio e estilo de aprendizagem. Para ela, neste novo processo educativo, o aluno dispõe de recursos para avançar, pausar, retroceder e rever o conhecimento. Assim, esse processo permite fazer anotações e investigações pessoais, consultar materiais alternativos e complementares, tanto como discutir com outros usuários ou com os próprios colegas suas produções. Assim, vemos que os recursos da informática não são o fim da aprendizagem, mas são meios que podem instigar novas metodologias que levem o aluno a aprender com interesse, com criatividade, com autonomia.

Para encerrar essa reflexão sobre o uso das novas tecnologias em nossas salas de aula, vejamos o que é afirmado nos Parâmetros Curriculares Nacionais do Ensino Médio (PCNEM, 2000).

Em sua Parte I - Bases Legais -, os PCNEM propõem “a formação geral, em oposição à formação específica; o desenvolvimento de capacidades de pesquisar, buscar informações, analisá-las e selecioná-las; a capacidade de aprender, criar, formular, ao invés do simples exercício de memorização”. (ibid, p.6)

De acordo com os PCNEM, essa nova sociedade, a qual é decorrente da revolução tecnológica e de seus desdobramentos na produção e na área da informação, apresenta características possíveis que podem assegurar à educação uma autonomia que ainda não foi alcançada, mas que isto só ocorrerá à medida que o desenvolvimento das competências cognitivas e culturais que são exigidas para o pleno desenvolvimento humano passe a coincidir com o que se espera na esfera da produção.

Já em sua Parte II - Linguagens, Códigos e suas Tecnologias -, os PCNEM observam que ter acesso ou não à informação leva à constituição de um elemento de discriminação na nova sociedade que está sendo organizada. O que atualmente pode-se constatar é o distanciamento entre os que conhecem e desconhecem o funcionamento dos computadores. Para os PCNEM, o estudante não pode ser visto como quem usa a informática enquanto instrumento de aprendizagem, mas deve ser visto também como 
"aquele que conhece os equipamentos, programas e conceitos que lhe permitam a integração ao trabalho e o desenvolvimento individual e interpessoal” (ibid, p. 59).

Após realizarmos uma discussão sobre a teoria sociointeracionista e o uso do computador, passamos à metodologia utilizada para o desenvolvimento deste estudo.

\section{Metodologia}

Para a realização dessa investigação, em nível de Pós-Graduação Lato Sensu, realizamos um estudo de caso uma vez que, segundo Telles (2002), os estudos de caso são utilizados quando o professor-pesquisador deseja enfocar um determinado evento pedagógico, componente ou fenômeno relativo à sua prática profissional. Johnson (1992) afirma que nos estudos de caso o pesquisador direciona sua atenção para uma única entidade, um único caso, provindo de seu próprio ambiente profissional que, no caso da nossa pesquisa, consistiu em um grupo de alunos de duas turmas de segundo ano do ensino médio de um colégio público da rede estadual de ensino de Goiás, localizado na cidade de Goiânia.

Para a análise dos dados deste estudo foram utilizados apenas os dados referentes aos alunos que estiveram presentes durante todo o semestre e cujos pais permitiram sua participação na pesquisa. Tendo em vista tais critérios, foram utilizados dados de 16 alunos, de ambas as turmas, cuja faixa etária variava entre 15 e 18 anos.

Em consonância com o método escolhido para a realização da pesquisa, utilizamos alguns recursos de coleta de dados como filmagens das aulas para poder auxiliar no processo de descrição das atividades, um diário de reflexões mantido pela professorapesquisadora e ainda questionários aplicados aos alunos sobre as atividades realizadas.

A pesquisa foi dividida em três partes, ou seja, em três projetos e cada um consistiu na realização de atividades envolvendo um programa de computador que independe de internet. Os programas utilizados foram: editor de textos (Word e BrOffice Writer), editor de slides (Power Point e BrOffice Impress) e editor de vídeos (Movie Maker). Em média, foram utilizadas 8 aulas para a realização de cada um dos projetos com todas as suas etapas. 
No primeiro projeto, no qual foi utilizado o editor de textos, foram enfocadas duas habilidades: a leitura e a produção escrita. Os alunos realizaram atividades de leitura e compreensão de textos enfocando o gênero textual 'cartão postal', além de produzirem cartões-postais, imprimi-los e, depois, organizarem um mural com esses cartões para que os outros alunos do colégio pudessem ver. O segundo projeto incluiu a utilização do editor de slides com o qual os alunos trabalharam também com a produção escrita. As apresentações incluíram temas de interesse dos alunos como futebol, pessoas famosas, lugares e cidades etc., comparando-os. Depois, para que os outros alunos da escola pudessem ter acesso ao trabalho por eles realizado, cada grupo fez um cartaz com seus slides impressos. Por fim, o terceiro projeto foi de utilização do editor de vídeos para que os alunos produzissem seus próprios vídeos e, depois, pudessem assisti-los e compartilhálos com os demais colegas. Algumas das temáticas abordadas nesse projeto foram: um documentário denunciando as más condições da escola, um documentário mostrando o que é ser uma fã de verdade, um documentário sobre a Aids, um outro sobre as olimpíadas que acontecerão no Rio de Janeiro em 2016 e um filme curto, contando a lenda da Maria Fumaça, estória essa criada pelos próprios alunos do Colégio.

A maioria das aulas aconteceu no laboratório de informática. Nele possuíamos 19 computadores e, para cada um, havia duas cadeiras. Contudo, em nenhuma aula pudemos contar com todos esses computadores funcionando.

Diante dos dados recolhidos, ou seja, as descrições das aulas, as atividades produzidas pelos alunos e os questionários, optou-se, para este artigo, trazer os resultados com relação ao uso do computador, como meio de motivá-los em nossas aulas de Inglês. Assim, passaremos a análise dos dados selecionados.

\section{Análise dos Dados}

A princípio, fizemos um primeiro questionário para que pudéssemos entender como as novas tecnologias estão presentes na vida dos alunos e como são utilizadas. A análise feita destaca que os alunos associam “computador”, “tecnologia” e “melhorias” aos recursos tecnológicos. Um dado curioso foi a resposta de uma aluna que relatou vir coisas 
complicadas à sua cabeça quando se fala em recursos tecnológicos, o que nos leva a perceber que nem todos os alunos estão tão familiarizados ou sabem lidar com recursos tecnológicos como pensamos que sabem. Percebemos, então, que, assim como afirmam Sampaio e Leite (1999), alguns alunos percebem que aprender a lidar com o computador e as novas tecnologias significa um meio para obter uma melhor condição social, mas que há percalços nesse caminho.

Outra pergunta desse questionário foi se os alunos conheciam ou já tinham ouvido falar de alguns programas (softwares) utilizados nos computadores e quais eram. Percebemos, por meio das respostas, que todos possuem certo conhecimento, uns mais e outros menos. Surge, a partir desse conhecimento de cada aluno, a cooperação mútua, pois um ajuda o outro com algo que o outro ainda não sabe e vice-versa. Dessa forma, percebemos que o trabalho em grupo pode favorecer a aprendizagem dos alunos, pois um apoia o outro para que os desafios possam ser superados, o que nos remete ao sociointeracionismo no qual um aluno serve como um suporte para o outro para que as atividades sejam realizadas.

Contudo, em outra pergunta, percebemos que a maioria dos alunos deseja que os computadores sejam mais utilizados para que eles possam obter informações, ou seja, que possam fazer mais pesquisas e que o computador os ajude a aprender mais. Assim, vemos que a vontade dos alunos vem ao encontro do que os autores como Masetto (2000) e Moran (2000) discorrem sobre a função do professor que se torna um mediador, uma pessoa que serve de ponte entre os alunos e a aprendizagem, para que os objetivos de aprendizagem sejam alcançados.

Ao longo das aulas percebemos que os alunos demonstraram um crescente interesse e, trabalhando em grupos, puderam ajudar uns aos outros a realizar suas tarefas corroborando assim com Vygotsky (1998) e a teoria sociointeracionista e com Paiva (2008) quando ela considera que o computador pode servir como um artefato indireto no suporte ao outro, nesse caso, o aluno. Foi possível perceber por meio da análise das aulas, que o computador, mais especificamente o editor de textos, ofereceu uma série de recursos que alguns alunos não conheciam e puderam explorar como, por exemplo, o tradutor e o 
dicionário de sinônimos, os quais serviram como um suporte para que eles desenvolvessem a atividade proposta.

Quando iniciamos a pesquisa, os alunos estavam estudando o passado simples, e a partir deste conteúdo, decidimos trabalhar com o gênero textual cartão-postal para que os alunos pudessem colocar em prática o que haviam estudado. Assim, eles deveriam fazer um cartão-postal em inglês descrevendo o que haviam feito nas últimas férias e deveriam fazê-lo utilizando o editor de textos.

Antes disso, realizamos a leitura e a interpretação de três cartões-postais em inglês e depois discutimos o gênero, ou seja, que tipo de texto era aquele, para que era usado, quais as características dele e o tipo de linguagem que pode ser utilizada quando escrevemos um cartão-postal.

Alguns depoimentos dos alunos mostram que eles perceberam seu aprendizado com relação ao que foi ensinado, pois eles relataram ter aprendido como diferenciar a escrita formal da informal, que puderam colocar em prática o que aprenderam (nesse caso, o passado simples) e que puderam aprender mais sobre as técnicas de leitura do inglês instrumental, tal qual os exemplos a seguir demonstram:

[01] Jessiane ${ }^{4}$ : Porque ao invés de ficar escrevendo textos, a gente se divertiu montando um belo cartão-postal e colocando em prática o que a gente aprendeu sobre a língua inglesa.

[02] Amanda: Nos ensinou a desenvolver a leitura e como entender melhor os textos.

[03] Rebeca: Pq aprendemos um pouco mais sobre como a Língua Inglesa é e conseguimos até compreender o que líamos.

[04] Maria Eduarda Felque: Percebi a diferença de escrever na forma formal, da informal.

Sobre esse primeiro projeto com o editor de textos, as alunas Rebeca e Raquel se destacaram não só por se aproximarem da língua-alvo e saberem combinar bem o fundo do cartão-postal com a fonte utilizada, como também por ajudarem os outros alunos os ensinando a fazer um cartão com imagem no fundo e a escrita por cima, pois eles não sabiam como fazer isso. Tais fatos corroboram com Monteiro, Neves et al. (2007) que

\footnotetext{
${ }^{4}$ Os nomes aqui apresentados são pseudônimos escolhidos pelos próprios participantes.
} 
afirmam que o computador pode ser utilizado como uma forma de trabalhar as capacidades cognitivas superiores, além de estimular o interesse dos alunos.

Pudemos perceber que a atividade de criação de cartões-postais exigiu mais esforço e criatividade dos alunos, além de um trabalho de bastante cooperação, de forma que um aluno pudesse servir de apoio a outro, conforme argumentam Vygotsky (2008) e Paiva (2008). Um aluno que sabia como colocar certo efeito no texto ou imagem, auxiliava outro; um que sabia um pouco mais de inglês auxiliava o outro com a língua, além de termos alunos que descobriram a ferramenta de tradução do editor de texto.

Outro fato que notamos é que podemos aliar recursos do computador à aula de língua inglesa, com ou sem a utilização de internet, e estimular nossos alunos para que eles queiram aprender e para que essa aprendizagem seja mais significativa, pois o aluno parte de algo que lhe interessa e que lhe é familiar para chegar ao objetivo final que é aprender inglês. Além disso, há ainda outros objetivos como se familiarizar com esses recursos tecnológicos e realizarmos, conforme sugere Demo (1991), uma democratização da informática em nossas escolas, pois quem sabe mais ajuda quem sabe menos e todos vão se familiarizando mais com essa ferramenta.

Ao final das atividades utilizando o editor de textos, percebe-se que os dados mostram que os alunos não só se divertiram e tiveram uma aula diferente, mas também sentiram que desenvolveram com relação ao aprendizado da língua, corroborando, assim, com as três vantagens que Pennington (1996) nos revela: as vantagens psicológicas, físicas e cognitivas.

Já com relação à utilização do editor de slides, antes de os alunos utilizarem essa ferramenta, o conteúdo linguístico que estava sendo trabalhado era formas de comparação. Depois da apresentação e de atividades de prática controlada (drills), foi pedido aos alunos que produzissem slides comparando coisas, pessoas, lugares etc.

Com o desenvolvimento dessa atividade, observamos que os alunos aprenderam não só as novas estruturas da língua se divertindo, mas também palavras e expressões novas, além de colaborarem uns com os outros no grupo como fica claro nos depoimentos a seguir: 
[05] Rebeca: Aprendi novas palavras e expressões.

[06] Sônia: Eu achei muito legal pois nos ajuda a desenvolver a nossa fala e escrita em Inglês.

[07] Maria Eduarda Felque: Porque podemos mostrar tudo o que a professora nos ensinou e porque eu aprendi como usar o comparativo e o superlativo.

[08] Dolls: Boa, porque aprendi coisas novas, as comparações e interessante porque eu gostei de procurar coisas para elaborar a atividade. [09] Juliana: Pois aprendemos muitas coisas trabalhando em grupo.

[10] Amanda: Porque foi divertido comparar as pessoas e lugares.

Conforme as informações obtidas por meio do questionário aplicado posteriormente aos alunos, percebemos que eles concordam com o uso de novas tecnologias para que se tenha uma aula melhor. Observamos que todos os alunos gostaram da atividade, uma vez que lhes possibilitaram aprender como criar e fazer slides, colocar em prática o que já sabiam e ainda aprender aspectos que não conheciam. Dessa forma, entendemos que, conforme afirmam Sampaio e Leite (1999), as tecnologias precisam ser parte do contexto escolar porque, além de fazer com que os alunos cheguem a conhecimentos de formas diferentes, o uso delas oferece um papel social importante, visto que permite a familiarização deles com várias tecnologias existentes, através da utilização delas, fazendo com que elas sejam desmistificadas e democratizadas. Tal utilização vai ao encontro dos pressupostos dos PCNEM (2000) que nos orientam para que possamos desenvolver competências que façam com que os estudantes obtenham e utilizem informações por meio do computador e que sejam sensibilizados para a presença de novas tecnologias em tudo que fazemos. Assim, observamos mais uma vez que, se o professor mantém um diálogo com seus alunos e assume seu novo papel proposto por Behrens (2000), Masetto (2000) e Moran (2000), entre outros autores, é possível realizar outras atividades utilizando o editor de slides, mesmo sem internet.

Por fim, começamos as atividades utilizando e editor de vídeos discutindo sobre tipos de filmes, programas de TV e música que os alunos gostavam. A discussão aconteceu em inglês e em português, pois quando os alunos não entendiam o que estava sendo perguntado, usava-se palavras chaves em português para ajudá-los a entender e os alunos respondiam às perguntas e davam suas opiniões em Português. Após essa discussão, foi proposto aos alunos que pensassem em um tipo de programa de TV ou de filme (nesse 
caso, um filme curto) que eles gostassem para, em grupos, produzirem um em inglês utilizando o editor de vídeos.

Observamos que, conforme afirma Jonassen (2000), o computador pode ser utilizado como uma ferramenta cognitiva para que nossos alunos desenvolvam um pensamento complexo, ou seja, trabalhem as funções psicológicas superiores. Nesse sentido, é importante ressaltar que é necessário que a aprendizagem aconteça com o computador e não sobre ou a partir dele.

Dessa forma, é necessário conhecermos bem as ferramentas computacionais, afinal, com toda a produção elaborada pelos alunos, entendemos que o computador e seus programas, quando utilizados como ferramentas cognitivas, podem desenvolver capacidades crítica e de reflexão. Tais capacidades são consideradas por Fontes (2002) como essenciais para que a aprendizagem se torne significativa e para que o conhecimento seja construído de maneira diferente.

Conforme mencionado anteriormente, o computador pode ser uma ferramenta cognitiva que proporciona uma aprendizagem significativa e que proporciona reflexão e crítica aos nossos alunos. Nesse sentido, o editor de vídeos pode promover uma mediação pedagógica a qual leva em conta as potencialidades desse meio tecnológico e que também possibilita trabalhos colaborativos, com a finalidade de promover a construção do conhecimento de nossos alunos.

Por meio das produções, observamos que houve alunos que usaram bastante a criatividade, outros que procuraram fazer um trabalho mais sério sobre temas atuais que têm sido bastante debatidos, como a Aids e problemas ambientais, além de alguns alunos terem utilizado essa oportunidade para fazerem denúncias sobre a situação em que se encontrava a escola deles. Enfim, por meio desses trabalhos, entendemos que aconteceu tanto colaboração entre os alunos, quanto uma aprendizagem significativa, proporcionadas pelo uso do computador, corroborando com os trabalhos de Fontes (2002), Paiva (2008), Vygostsky (1998), Moran (2000), entre outros autores.

Após a finalização do projeto, foi aplicado outro questionário que visou saber a opinião dos alunos sobre essas atividades utilizando o editor de vídeos. A primeira pergunta do questionário procurou saber a opinião dos alunos sobre as atividades 
realizadas com a ferramenta. Com relação à elaboração dos vídeos, observamos que todos os alunos gostaram da atividade, sendo que, a maioria a considerou excelente, pois, conforme as justificativas apresentadas a seguir, eles consideraram que puderam ampliar seus conhecimentos com relação à informática e o uso do editor de vídeos, além de aprenderem sobre a língua inglesa falando sobre algo que gostam:

[11] Thomas: Amplia nossos conhecimentos na área da informática.

[12] Dione: Acho legal porque é dinâmico e da bastante espaço pra se abordar várias coisas.

[13] Maria Eduarda: Aprendi como fazer um vídeo.

[14] Jessiane: Porque é uma forma que leva os alunos a se interessarem a fazer os trabalhos escolares.

[15] Ana: Eu adorei fazer a elaboração foi muito legal mesmo pois a professora nos ajudou muito. Eu fiz o vídeo sobre algo que eu adorei.

Por meio desses depoimentos percebemos, também, a realidade do que nos afirma Demo (1991, apud Sampaio e Leite, 1999) sobre o aspecto social do uso das novas tecnologias nas aulas.

Com relação à segunda atividade que foi a de apresentação dos vídeos, observamos a mesma aceitação citada anteriormente. As alunas Ana e Juliana, por exemplo, consideraram a atividade excelente e justificam, respectivamente, que "A apresentação foi melhor ainda pois fiquei muito impressionada com o resultado.” E "percebemos qual é a possibilidade de cada um construir um vídeo em Inglês.” E a aluna Maria Eduarda que considerou a aula boa justifica que "Alguns vídeos foram bons e outros ruins e não dava para ler a tradução”. Assim, através das justificativas confirmamos mais uma vez a importância da interação para o desenvolvimento dos alunos, conforme Vygotsky (1998) e Paiva (2008). Percebemos também que a aprendizagem colaborativa pode ser eficaz para que os alunos se ajudem e alcancem o objetivo final dessas atividades feitas por eles que é a aprendizagem da língua inglesa.

Com relação à elaboração dos vídeos, percebemos, também, que os alunos gostam de novos desafios, como gravar um vídeo com legendas em inglês ou até mesmo vídeos em inglês, o que corrobora com a afirmação de Masetto (2000, p. 152) de que "o professor tem um importante papel como um agente promotor do processo de aprendizagem do aluno, 
que constrói o conhecimento num ambiente que o desafia e o motiva para a exploração, a reflexão, a depuração de ideias e a descoberta de novos conceitos”. Nesse sentido, temos as justificativas das alunas Sônia e Juliana que consideraram a atividade excelente, pois, afirmaram, respectivamente, "nos ensina muito mais do que se fosse na sala de aula" e “Aprendemos a falar algumas coisas, aprendemos a escrever” e dos alunos Dione e Amanda que consideraram a atividade boa, respectivamente, "Bom, porque temos que traduzir muito, correr atrás e ele torna uma coisa legal” e “ Deu pra aprender com a ajuda da tradução”.

Em relação à apresentação dos vídeos, percebemos que, apesar das dificuldades enfrentadas para elaborar os vídeos e assisti-los também, os alunos conseguiram aprender algo novo e puderam se desenvolver mais, conforme as justificativas dos alunos Dione, Juliana, Daniela, Maria Eduarda Felque, Ana e Sônia, que consideraram a atividade boa e excelente, atestam:

[16] Dione: Bom, porque assim a gente aprende junto com os outros alunos, os que fizeram o vídeo.

[17] Juliana: vimos a opinião de cada um a respeito do tema.

[18] Daniela: Além de aprender fazendo o meu, aprendi assistindo o dos meus colegas.

[19] Maria Eduarda Felque: Eu pude aprender palavras novas com os trabalhos dos meus colegas.

[20] Ana: Sim, foi muito boa a apresentação, pois vi que sou capaz de fazer isso e muito mais.

[21] Sônia: É legal porque vemos o desenvolvimento dos nossos colegas também.

Percebemos, assim, que tais afirmações mostram que os alunos sabem que podem aprender uns com os outros, que eles podem trabalhar de forma colaborativa para obter um bom resultado final.

Já outro questionamento é se os alunos acham que conseguiram aprender mais nas aulas de inglês com o uso de recursos tecnológicos e, de acordo com os questionários, houve unanimidade nas respostas positivas, tal qual vemos nos relatos a seguir:

[22] Dione: Porque em vez de me jogarem a aula de inglês na cara, eu fui atrás dele. 
[23] Maria Eduarda: “Muito, aprendi palavras e como são algumas regras. [24] Raquel: Eu já sabia um pouco, com as aulas comecei a desenvolver melhor.

[25] Dolls: Um pouco sim, aonde coloca os verbos nas frases.

[26] Daniela: Sim. Porque a aula era mais divertida e fazia com que todos se divertissem e aprendessem mais inglês.

[27] Maysa: pois aprendi a escrever melhor Inglês.

Verificamos por meio desses depoimentos, então, que esses dados reforçam as afirmações de Paiva (2008) que considera que o computador pode ser utilizado como um artefato que auxilia na aprendizagem do aluno, que pode proporcionar a interação necessária para ele e o seu desenvolvimento também.

Procuramos saber se, com relação às atividades, os alunos gostaram de elas terem sido realizadas em grupo ou se eles prefeririam fazê-las individualmente. Mais uma vez, todos os participantes responderam que prefeririam em grupo, o que reforça a abordagem colaborativa de aprendizagem, no qual um aluno colabora com o outro, um aluno oferece suporte ao outro para que cheguem ao objetivo: a aprendizagem da língua. Os excertos abaixo confirmam tais afirmações:

[28] Thomas: Porque pega um pouco de conhecimento de cada um e facilita na hora da aprendizagem.

[29] Maria Eduarda: Em grupo é melhor pois aparecem muitas idéias.

[30] Raquel: Gostei de fazer as atividades em grupos porque se um estiver com dificuldade, o outro ajuda.

[31] Ana: Em grupo pois assim aprendemos com os colegas que sabem algo a mais e também o que a gente sabe também passa para eles.

Por fim, foi perguntado aos alunos se eles gostariam que as aulas de inglês continuassem como foram no semestre, utilizando recursos tecnológicos e pudemos observar que todos os alunos responderam afirmativamente, mesmo com todos tendo enfrentado problemas como o datashow não funcionando, arquivos perdidos e refacção do trabalho etc. Tais dados corroboram os estudos de Pennington (1996) sobre as vantagens psicológicas, físicas e cognitivas do uso do computador para a aprendizagem.

A seguir, temos alguns depoimentos que corroboram com as teorias apresentadas nessa pesquisa, como a aprendizagem colaborativa de línguas e o uso do computador sob 
uma influência sociointeracionista, de forma a proporcionar uma aprendizagem significativa, lúdica e que proporcione a interação dos alunos entre eles e com as ferramentas oferecidas pelo computador para a realização das atividades propostas.

[32] Kael: com o tradutor aprendemos várias palavras e trabalhar em grupo é menos "carga na mente".

[33] Maria Eduarda Felque: Eu pude exercitar o que aprendi em Inglês, usando recursos tecnológicos é mais incentivador e trabalhar em grupo e melhor porque um ajuda o outro.

[34] Dolls: aprendi aonde colocar os verbos nas frases e com os recursos tecnológicos é mais divertido.

[35] Dione: Porque ao invés de jogarem a aula de inglês na cara, eu fui atrás dele usando os recursos tecnológicos disponíveis.

[36] Rebeca: Em grupo é melhor porque além de ser mais fácil, uma ajuda o outro.

[37] Thomas: Em grupo, porque pega um pouco de conhecimento de cada um e facilita na hora da aprendizagem.

Após essa análise sobre o que foi ensinado e aprendido pelos alunos, os resultados com relação ao uso da Língua Inglesa e o uso do computador, mesmo sem internet, como meio de motivar nossos alunos em nossas aulas de Inglês, passaremos, a seguir, a algumas considerações finais.

\section{Considerações Finais}

A pergunta que faz parte do título deste artigo - “Fessora, não tem internet, não?” era recorrente nas primeiras vezes em que íamos ao laboratório de informática e mostra que sempre há a associação do computador com a internet. Neste estudo, percebemos que, apesar dos problemas com os quais lidamos quando utilizamos recursos tecnológicos em nossas escolas, em especial os computadores, pudemos constatar que, apesar de terem existido problemas de ordem técnica ao longo da pesquisa, conseguimos atingir o objetivo principal que era o de encontrar formas de se utilizar os novos recursos tecnológicos, independente de ter ou não internet, de uma maneira eficiente para uma melhor aprendizagem da língua inglesa e de forma que motivasse os alunos. 
Um fato notável foi o de como os alunos foram adquirindo certa autonomia ao longo das aulas, pois eles procuravam ajuda com os colegas que sabiam mais, deixando apenas as dúvidas com relação ao inglês para serem solucionadas com a professora. Era gratificante ver os alunos tentando utilizar os tópicos ensinados e muitas vezes acertando ou errando, ou melhor dizendo, criando hipóteses sobre a utilização do que havia sido aprendido. Ao fim, foram produzidos ótimos trabalhos e bem criativos que nos deixaram encantadas pela qualidade e pelo empenho deles em realizar as atividades, principalmente as de produção.

Assim, ao final dessa pesquisa, ao retomarmos a pergunta que a motivou que era a de como utilizar o computador, independentemente de internet, de forma eficiente para motivarmos mais nossos alunos, percebemos que essa motivação aparece ao longo das atividades, tal qual pudemos observar por meio dos dados.

Pensamos que, além de usar o computador como um recurso no ensino de língua inglesa, podemos promover a inclusão e letramento digital de alguns alunos que não conhecem programas básicos do computador e que hoje são importantes para a ascensão social deles ou que conhecem, mas não possuem acesso fácil a essas tecnologias para utilizá-las. Dessa forma, vemos que o professor tem a possibilidade de não só trabalhar com o ensino da língua inglesa e aspectos referentes a ela usando novas tecnologias, como também promover a democratização do seu uso, permitindo que nossos alunos se desenvolvam tanto no que concerne à aprendizagem de língua quanto ao que se refere ao desenvolvimento social deles.

Assim, encerramos este artigo procurando mostrar aos colegas, professores de escolas públicas que, apesar de todas as dificuldades que enfrentamos em nossa profissão, podemos fazer bons trabalhos com nossos alunos. Basta querermos e nos esforçarmos para alcançar nossos objetivos.

\section{Referências}

BEHRENS, M. A. Projetos de aprendizagem colaborativa num paradigma emergente. In: BEHRENS, M. A.; MASETTO, M. T.; MORAN, J. M (Org.). Novas tecnologias e 
mediação pedagógica. SP: Papirus, 2000. p. 67-132.

BRASIL. Ministério da Educação. Secretaria de Educação Média e Tecnológica. Parâmetros Curriculares Nacionais para o Ensino Médio. Brasília: MEC, 2000.

DEMO, P. Educação e desenvolvimento: algumas hipóteses de trabalho frente à questão tecnológica. Revista Tempo Brasileiro. RJ, n. 105, p. 149-170, abr./jun. 1991.

FONTES, M. C. M. Aprendizagem de inglês via internet: descobrindo as potencialidades do meio digital. 2002. 217 f. Tese (Doutorado em Linguística Aplicada ao Ensino de Línguas) - Pontifícia Universidade Católica de São Paulo, São Paulo, 2002.

JOHNSON, D. M. Approaches to research in second language learning. NY: Longman, 1992.

JONASSEN, D.H. Computer as Mindtools for Schools: Engaging Critical

Thinking. New Jersey: Prentice-Hall, 2000.

LANTOLF, J. P. Introducing sociocultural theory. In: LANTOLF, J. P. (Ed.), Sociocultural theory and second language learning. Oxford: Oxford University Press, 2000. p. 1-26.

LEITE, L. S.; SAMPAIO, M. N. Alfabetização tecnológica do professor. RJ: Vozes, 1999. MARTINS FONTES, M. C. M. Aprendizagem de inglês via internet: descobrindo as potencialidades do meio digital. 2002. 217 f. Tese (Doutorado em Linguística Aplicada ao Ensino de Línguas) - Pontifícia Universidade Católica de São Paulo, São Paulo, 2002.

MASETTO, M. T. Mediação pedagógica e o uso da tecnologia. In: BEHRENS, M. A.; MASETTO, M. T.; MORAN, J. M (Org.). Novas tecnologias e mediação pedagógica. SP: Papirus, 2000. p. 133-173.

MONTEIRO, A. et al. MPEL - Percursos de aprendizagem mediados por ferramentas tecnológicas, 2007. Disponível em: <http://educivica.com.sapo.pt/EAT_Blogs.pdf>. Acesso em: 08 maio 2009.

MORAN, J. M. Novas tecnologias e o re-encantamento do mundo. Tecnologia Educacional. Rio de Janeiro, vol. 23, n.126, set.-out. 1995, p. 24-26. Disponível em: <http://www.eca.usp.br/prof/moran/novtec.htm>. Acesso em: 08 maio 2009.

Ensino e aprendizagem inovadores com tecnologias audiovisuais e telemáticas. In: BEHRENS, M. A.; MASETTO, M. T.; MORAN, J. M (Org.). Novas tecnologias e 
mediação pedagógica. SP: Papirus, 2000. p. 11-65.

PAIVA, V. L. M. O. O outro na aprendizagem de línguas, 2008. Disponível em: <http://www.veramenezes.com/outro.pdf>. Acesso em: 17 jun. 2009.

PENNINGTON, M. C. The Power of CALL. NY: Athesltan, 1996.

TELLES, L. “É pesquisa, é? Ah, não quero, não bem!” Sobre a pesquisa acadêmica e sua relação com a prática do professor de línguas. Linguagem e Ensino, v. 5, n. 2, 2002. p. 91116.

VYGOTSKY, L. S. A formação social da mente: o desenvolvimento dos processos psicológicos superiores. SP: Martins Fontes, 1998.

L. S. A construção do pensamento e da linguagem. S. Paulo: Martins Fontes, 2001. 